\title{
AS ESTRATÉGIAS DE ENSINO-APRENDIZAGEM UTILIZADAS PELOS DOCENTES E SUA RELAÇÃO COM O ENVOLVIMENTO DOS ALUNOS ${ }^{1}$
}

\section{STRATEGIES FOR TEACHING-LEARNING USED BY TEACHERS AND THEIR RELATIONSHIP WITH THE INVOLVEMENT OF STUDENTS}

\author{
Simone Alves da Costa ${ }^{2}$ \\ Doutoranda em Controladoria e Contabilidade pela USP \\ simone.ac@gmail.com \\ Maria de Las Mercedes Pfeuti \\ Mestranda em Controladoria e Contabilidade pela USP \\ maria@descon.com.br \\ Silvia Pereira de Castro Casa Nova \\ Doutora em Controladoria e Contabilidade pela USP \\ Professora do Programa de Pós-Graduação em Controladoria e Contabilidade da USP \\ silvianova@usp.br
}

\section{RESUMO}

O objetivo deste artigo é analisar o impacto na utilização de diferentes estratégias de ensinoaprendizagem pelos professores, levando-se em conta a forma de estudo que se pretende que os alunos adotem em um curso de pós-graduação em Ciências Contábeis, entre elas as abordagens superficial e profunda de aprendizagem. Foram testadas duas modalidades didáticas durante duas aulas, sendo: uma aula tradicional, composta de aula expositiva e resolução de exercícios (aula 1); e uma aula prática, tendo sido desenvolvido material a ser utilizado em sala de aula com apoio da Taxonomia de Bloom e das teorias sobre as abordagens de aprendizagem (aula 2). Nessa proposta, entende-se que a aula tradicional estaria mais ligada a uma abordagem superficial de aprendizagem, enquanto o material produzido para a aula 2 levaria ao alcance de uma abordagem profunda de aprendizagem, dado que propicia maior participação e interação dos alunos com o conteúdo proposto. Como resultado, não foram percebidas diferenças significativas em relação às duas modalidades didáticas. No que tange à abordagem superficial e profunda, a modalidade proposta para a aula 2 foi mais efetiva no sentido de garantir a participação dos alunos, bem como seu envolvimento no sentido de buscar aplicações práticas e estabelecer relações entre a teoria e a prática. Já no que diz respeito às categorias inerentes ao domínio cognitivo da Taxonomia de Bloom, os dois métodos se mostraram eficazes no alcance das diferentes vertentes investigadas, a saber, aula expositiva e aula prática. Ressalta-se, no entanto, que a segunda modalidade, aula prática, permite desenvolver objetivos relacionados também ao domínio afetivo da taxonomia.

Palavras-chave: Aluno Superficial e Profundo. Modalidade didática. Taxonomia de Bloom.

\footnotetext{
${ }^{1}$ Recebido em: 19/02/2014. Revisado por pares em: 27/03/2014. Segunda versão recebida em: 12/04/2014. Recomendado para publicação em: 15/04/2014 por Orleans Silva Martins (Editor Geral). Publicado em: 30/04/2014. Organização responsável pelo periódico: UFPB.

${ }^{2}$ Endereço: Av. Prof. Luciano Gualberto, 908, Prédio FEA3, Cidade Universitária, CEP 05.508-900, São Paulo/SP. DOI: http://dx.doi.org/10.18405/recfin20140104
} 


\section{ABSTRACT}

The objective of this paper is to analyze the impact of using different strategies of teaching and learning by teachers, taking into account the form of study that is intended that students adopt in a course graduate in Accounting, among them surface and deep learning approaches. Two teaching methods were tested for two classes, namely: a traditional class, composed of lecture and practical classes (class 1); and a practical session, materials to be used in the classroom with the support of Bloom's Taxonomy and theories on learning approaches (class 2 ) has been developed. In this proposal, it is understood that the traditional classroom would be more related to a surface approach to learning, while the material produced for class 2 would lead to the achievement of a deep learning approach, because it provides greater participation and student interaction with content proposed. As a result, no significant differences for the two teaching methods were perceived. Regarding the superficial and deep approach, the proposal to class 2 modes was more effective in ensuring the participation of students as well as their involvement in seeking practical applications and linking theory and practice. In what regards the categories inherent in the cognitive domain of Bloom's Taxonomy, the two methods have proved effective in achieving the various aspects investigated, namely, lecture and practical class. It is noteworthy, however, that the second mode, practical class, also allows you to develop goals related to the affective domain taxonomy.

Keywords: Student Superficial and Deep. Didactic mode. Bloom's Taxonomy.

\section{INTRODUÇÃO}

As estratégias de ensino-aprendizagem (ou modalidades didáticas) são recursos utilizados no cotidiano do professor, a fim de buscar assegurar aos estudantes alternativas que auxiliem no atingimento dos objetivos de aprendizagem estabelecidos. Machado (2001) afirma que são quatro os verbos principais que deveriam figurar na ação do professor: mediar, tecer, mapear e construir. Mediar envolve gerenciar os conflitos que surgem entre a ação docente e o processo de aprendizado do discente. Tecer envolve gerar significado ao conhecimento que está sendo transmitido, de forma que esse passe a fazer sentido no universo do educando. Mapear significa trazer ao aluno o que é relevante, fazendo amarrações entre o tema e o meio que o circunda, na escala adequada ao tempo e profundidade desejados, de forma a novamente trazer significado. Por último, construir implica em contar narrativas, por meio das quais a retenção do conhecimento possa ser facilitada e o aprendizado se torne mais interessante e prazeroso.

Dessa forma, cabe ao professor a tarefa de decidir de que maneira o conhecimento pretendido chegará ao aluno, enfatizando mecanismos de dependência ou de independência em relação à figura do professor. Santos (2008) argumenta que a busca por alternativas e reflexões sistemáticas inerentes aos problemas pedagógicos pode ser entendida como didática.

O uso da didática se operacionaliza por meio de técnicas de ensino-aprendizagem, que podem levar os alunos, segundo Ramsden (2000), a apresentarem diferentes comportamentos de estudo. São as abordagens de aprendizagem que Ramsden (2000) descreve como superficial e profunda. Essas abordagens, oriundas da tipologia de Convington (PERRY; SMART, 1997), enfatizam diferentes posturas no aluno, ou seja, distinguem a forma como o estudante responde ao processo de ensino-aprendizagem.

$\mathrm{Na}$ abordagem superficial, as atitudes do aluno são mais passivas, esperando obter do professor um conteúdo a ser reproduzido. Já a abordagem profunda enfatiza a energia e pró-atividade do estudante no sentido de tentar compreender determinado assunto, mapear relações entre temas e construir o conhecimento. A abordagem do professor como facilitador auxilia o estudante a relacionar conhecimentos e construir significados, reforçando a ideia de Machado (2001), mencionada anteriormente. 
A Taxonomia de Bloom propicia a classificação de abordagens de aprendizagem, auxiliando na organização de disciplinas (SANTANA et al., 2008) e englobando os domínios cognitivo, afetivo e psicomotor (BLOOM, 1973). Na presente pesquisa, entende-se que o desenvolvimento do domínio cognitivo, que na Taxonomia de Bloom se refere às capacidades envolvendo conhecimento, compreensão, aplicação, análise, síntese e avaliação (BLOOM, 1973), pode ser afetado pela escolha da modalidade didática. Neste trabalho, acredita-se que a estratégia de ensino-aprendizagem utilizada pelo professor influencia a forma de estudo adotada pelo aluno, bem como seu nível de aprendizado.

Para fins desta proposta, a aula tradicional estaria mais ligada a uma abordagem superficial de aprendizagem, enquanto a aula prática poderia levar ao alcance de uma abordagem profunda de aprendizagem, dado que propicia maior participação e interação dos alunos com o conteúdo proposto. Assim, entrelaçando tais pontos, chega-se à seguinte questão de pesquisa: qual é o impacto da estratégia de ensino-aprendizagem adotada em relação à forma de estudo - superficial ou profunda - adotada pelos alunos nos cursos de pós-graduação em Ciências Contábeis?

O objetivo deste artigo é analisar o impacto na utilização de diferentes estratégias de ensino-aprendizagem pelos professores, levando-se em conta a forma de estudo que se pretende que os alunos adotem - superficial ou profunda - nos cursos de pós-graduação em Ciências Contábeis. Como objetivo secundário, pretende-se discutir criticamente a perspectiva das abordagens de aprendizagem, principalmente quanto à sua aplicabilidade dentro das modalidades de ensino utilizadas nos cursos de pós-graduação em Contabilidade. $\mathrm{O}$ estudo foi realizado em uma turma de pós-graduação em Ciências Contábeis na disciplina de Controladoria durante os meses de outubro e novembro de 2012.

Esse estudo trata sobre o conjunto das estratégias de ensino-aprendizagem e das abordagens de estudo dos alunos pode fornecer um panorama de qual forma de estudo os alunos dos cursos de pós-graduação em Ciências Contábeis têm sido incentivados a adotar em função das modalidades didáticas adotadas pelos docentes, ainda que essa relação não seja diretamente aplicável a todos os estudantes, uma vez que pode ser influenciada também por outros fatores.

Além disso, tem-se uma contribuição científica, por se desbravar o campo de estudos das modalidades didáticas em conjunto com as abordagens superficial e profunda de aprendizagem, que pode influenciar pesquisadores e professores a, respectivamente, produzirem mais pesquisas sobre esses temas e refletirem sobre as estratégias de ensino-aprendizagem por eles adotadas, tendo em vista uma abordagem de estudo desejada para os alunos.

\section{REFERENCIAL TEÓRICO}

Como parte deste estudo, pretende-se discorrer sobre os principais temas que estão envolvidos com a questão pesquisada, a saber, as modalidades didáticas e as abordagens de estudo e aprendizagem. O primeiro tema diz respeito às formas de ensino adotadas pelos professores, principalmente as que são predominantemente estudadas pela andragogia, ou seja, o processo de ensino-aprendizagem voltado para adultos. No segundo, considera-se que as abordagens superficial e profunda influenciam diretamente no alcance dos objetivos de aprendizagem pretendidos pelos docentes, pois estão relacionadas ao comprometimento e envolvimento dos alunos com o próprio aprendizado.

Outro enfoque também importante para entender os temas considera que, entre os alunos, há diferenças nos níveis de profundidade e abstração de conhecimento, mesmo sendo expostos aos mesmos recursos de ensino-aprendizagem (BLOOM, 1973; BLOOM; KRATHWOHL; MASIA, 1974). Assim, há outros fatores que podem influenciar o envolvimento e a retenção de conhecimento por parte do discente, que circundam o tema desta pesquisa, como descrito nas seções seguintes. 


\subsection{Modalidades Didáticas}

Santos (2008) coloca que a didática consiste em refletir continuamente e buscar alternativas para os problemas das práticas pedagógicas. Tal reflexão auxilia no estudo das teorias de ensinoaprendizagem e seus resultados no processo. Para Santos (2008), o interesse da didática está relacionado a todo o conteúdo aprendido da parte do aluno na relação com o professor e o grupo, por meio do processo de aprendizagem que é realizado. Já Godoy (1988), afirma que o estudo da disciplina de Didática é útil aos professores, pois pode ajudá-los no que concerne à sua atuação propriamente dita, bem como no que diz respeito à reflexão acerca da efetivação prática de propostas relacionadas à didática.

Por sua vez, DeAquino (2007) estuda as práticas voltadas ao ensino de adultos: a andragogia. Para ele, são dois os principais tipos de abordagens voltadas à aprendizagem: (a) a aprendizagem direcionada: centrada no professor e mais popularmente usada no Ensino Superior, predominantemente com aulas expositivas e (b) a aprendizagem facilitada: centrada no aprendiz e mais apropriada para o ensino voltado a adultos.

Neste caso, DeAquino (2007) considera que a aprendizagem facilitada pode ser autodirecionada, ou seja, dar incentivo ao papel dos professores como facilitadores, favorecendo a cooperação entre professor e aluno e com foco maior no processo do que no conteúdo, visando desenvolver habilidades e atingir metas individuais. Outra abordagem que a aprendizagem facilitada pode assumir é a de aprendizagem transformadora, que aponta para a reflexão crítica sobre as suposições, as crenças e os valores individuais, dando maior ênfase à autonomia e à responsabilidade social do aluno. Esse tipo de aprendizagem poderia causar o que DeAquino (2007) chama de efeito "Pigmalião": as pessoas podem ter um desenvolvimento pessoal se sentirem um ambiente de confiança e incentivo à sua volta. Finalmente, o autor apresenta a aprendizagem vivencial, mais popularmente conhecida por meio do Ciclo de Kolb, que estimula a experiência em detrimento à passividade (Figura 1).

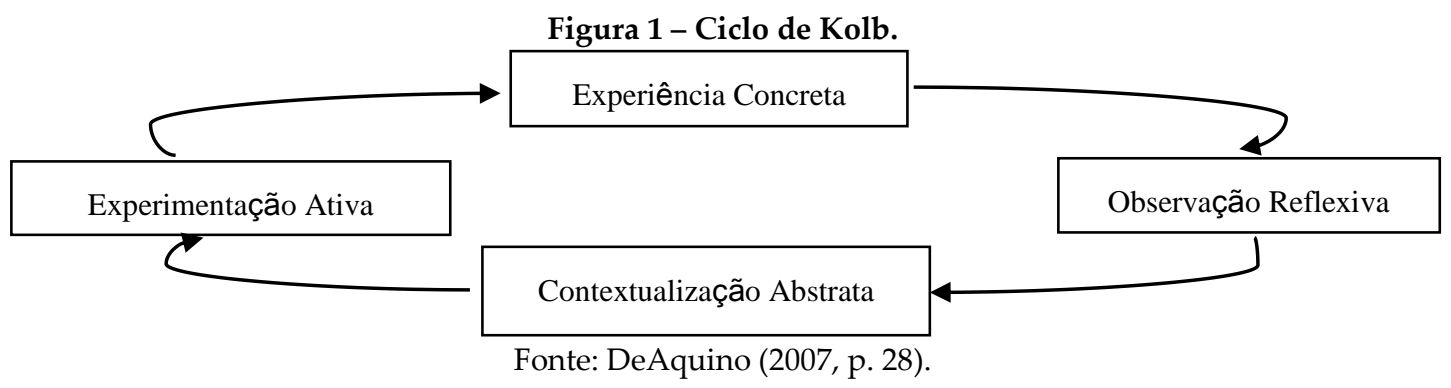

A Figura 1 apresenta o Ciclo de Kolb que parte da ideia que a experiência concreta faz o aluno aprender sobre algum tema por meio de vivência e envolvimento direto. Em seguida, a observação reflexiva auxilia o discente a pensar criticamente sobre a experiência. A contextualização abstrata, por sua vez, é uma etapa que conecta a experiência com a teoria e os conceitos que a fundamentam. Finalmente, a experimentação ativa faz com que aluno aplique o que foi aprendido aos conceitos na vida real.

DeAquino (2007) coloca que o conhecimento, neste modelo, é saber algo por experiência própria, ou seja, "aprender fazendo", ou ainda, "aprender colocando a mão na massa", e destaca que o aluno pode desenvolver um senso de percepção do que é e do que não é útil, dentro das diversas opções que ele possui acesso hoje dentro da literatura da área de negócios. Desta forma, ele aprende a maneja o conhecimento para seu crescimento.

Souza (2006) destaca que, somente em aulas mais voltadas à prática, o aluno pode ter contato direto com processos e enfrentar problemas, inicialmente não previstos, que estimulem seu raci- 
ocínio e imaginação para chegar a uma solução. Neste caso, o papel do professor é importante para facilitar a reflexão sobre qual deve ser a atuação do aluno.

Segundo Hosal-Akman e Simga-Mugan (2010), a aprendizagem ativa envolve os alunos e os ajuda a aprender o relacionamento entre o conhecimento e a prática. Para isso, seria interessante a utilização de materiais visuais, estratégias que encorajem os alunos a escrever e tomar notas, utilização de tecnologia em sala de aula, resolução de problemas, jogos, simulações de problemas e estudo cooperativo.

Lima (2012) descreve que a aprendizagem cooperativa põe seu foco na interação e cooperação entre os alunos. Destaca também a figura do professor como facilitador, para que as aulas possam ter êxito, bem como a questão voltada à responsabilidade compartilhada com os alunos, para que o conhecimento possa ser alcançado. Ela destaca algumas abordagens de aprendizagem mais voltadas para alunos de Ensino Superior, a saber: aula expositiva, estudos de casos, role-play, simulações e discussões em pequenos grupos, entre outras. A determinação de qual método utilizar, em geral, fica a critério do professor, de acordo com os objetivos, disponibilidade de tempo e recursos que se tem para ministrar a aula (KRASILCHICK, 2000; PETRUCCI; BATISTON, 2006). Poucas são as instituições que adotam uma modalidade de ensino preferencial e estimulam os professores a se capacitarem a utilizá-la de forma frequente.

Leal e Cornachione Jr. (2006), em pesquisa com discentes e docentes, bem como com a utilização de dados públicos (Exame Nacional de Cursos - "Provão"), investigaram o uso da aula expositiva que, supostamente, estimularia um espírito de passividade nos alunos, levando-os a um comportamento pouco crítico e de baixo nível de participação. Foi constatado que em cursos onde havia predominância de mescla de métodos didáticos em detrimento à aula expositiva exclusivamente, os alunos demonstraram maior nível de desenvolvimento de competências de formação.

Buckhaults e Fisher (2011) argumentam que o incremento de novas técnicas ao ensino da contabilidade pode ser o antídoto para a diminuição da procura pelos cursos nos EUA, bem como para aumentar a atratividade da área para o estudante. Para os autores, as novas técnicas podem promover o uso de ferramentas diferenciadas para desenvolver habilidades de análise, tomada de decisão e comunicação, pouco usuais nas metodologias de ensino convencionais em contabilidade.

Opdecam e Everaert (2012) demonstraram que o investimento de tempo em uma metodologia de ensino que privilegiasse o aprendizado em equipe, tendo no professor a figura de facilitador, aumentou os níveis de aprendizado e desempenho dos estudantes. Com isso, o nível de satisfação de turmas do primeiro ano no ensino de contabilidade foi aumentado. Na sequência, são abordadas outras perspectivas de aprendizagem, centradas na figura do aluno.

\subsection{Abordagens de Aprendizagem}

Para Luckesi (1994), as modalidades de ensino trazem consequências para a prática docente. Na definição de procedimentos de ensino é necessário ter uma proposta pedagógica e entender que os procedimentos de ensino adotados são mediações dessa proposta, e devem estar estreitamente articulados para que se obtenham resultados positivos. Os procedimentos metodológicos devem operacionalizar os resultados desejados.

Perry e Smart (1997) descrevem quatro tipos de abordagens, segundo a tipologia de Convington, as quais se podem tipificar os alunos que tem habilidades em comum, a saber: 1) Overstrivers (super-esforçados) - são autoconfiantes, bons estudantes, muito ansiosos e estudam muito tempo; 2) Success-Oriented (orientados para o sucesso) - são autoconfiantes e bons alunos também, porém tem uma baixa ansiedade e um tempo mais moderado de estudo; 3) Failure-Avoiding (evitam o fracasso) - têm dúvidas sobre si mesmos, um pouco de dificuldade para estudar, ansiedade alta e utilizam pouco tempo de estudo; e 4) Failure-Accepting (aceitam o fracasso) - têm dúvidas 
sobre sua capacidade, um pouco de dificuldade de compreensão, ansiedade baixa e utilizam pouco tempo para estudar.

Covington, Perry e Smart (1997) sugerem que os professores, independente da metodologia de aprendizagem adotada, promovam a autoestima dos discentes por meio de tarefas envolventes e desafiadoras, se assegurem de que todos os alunos compreendam as tarefas propostas e forneçam feedback rotineiramente sobre o desempenho; organizem o conteúdo, estruturando o conhecimento e as ideias, inter-relacionando-os; e melhorem a percepção do que estiver sob seu controle, além de promover novas práticas de ensino, modificando as atuais e percebendo as diferenças que provocam entre os alunos.

Petrucci e Batiston (2006) observam que as estratégias utilizadas não são absolutas, nem imutáveis, constituindo-se em ferramentas que podem ser adaptadas, modificadas ou combinadas pelo docente, conforme julgar conveniente, de acordo com seus objetivos. Além da tipificação dos alunos em relação as suas características pessoais e seu tempo de dedicação ao estudo, outras abordagens de aprendizagem relevantes são descritas nas seções seguintes.

\subsubsection{Aluno Superficial e Aluno Profundo}

Para Spencer (2003), as abordagens de estudo dos alunos são classificadas como profunda e superficial. Na abordagem profunda o aluno é participante, consegue ver aplicações práticas e relaciona a teoria que aprendeu. $\mathrm{O}$ aluno também é crítico e busca soluções aos problemas que surgem. Já na abordagem superficial, o aluno apenas memoriza e reproduz as informações, para cumprir a obrigação do momento. Ele não tem domínio do conhecimento específico e generalizado e raramente encontra aplicação prática no que está aprendendo.

Spencer (2003) explica que os fatores que podem determinar se os alunos irão adotar uma ou outra abordagem se devem a características inerentes aos estudantes ou a como respondem a fatores externos situacionais. Neste ponto, pode-se exemplificar como fator externo situacional a modalidade didática adotada pelo docente. $\mathrm{O}$ autor sugere que a abordagem superficial está mais associada a um menor sucesso acadêmico e a abordagem profunda está associada a um maior sucesso, interesse e entusiasmo pelo conhecimento. Os resultados da pesquisa mencionam que os educadores em contabilidade devem incentivar uma abordagem profunda nos alunos para que eles possam ter uma postura crítica e não somente ser repetidores de regras, como na abordagem superficial.

Hall et al. (2004) analisaram a utilização de abordagens profundas para a aprendizagem, como forma de aumentar a participação dos alunos e desenvolver o raciocínio analítico e conceitual. Foram pesquisados docentes que estivessem dispostos a adotar estratégias diferenciadas no ensino em contabilidade. Os resultados indicaram que, em todo o semestre, os estudantes apresentaram um aumento pequeno, mas estatisticamente significativo, na abordagem de aprendizagem profunda, e uma redução pequena, mas estatisticamente significativa, na abordagem de aprendizagem superficial. Os resultados sugerem que, por meio de mudanças no ambiente de aprendizagem, os educadores podem influenciar as abordagens de estudo adotadas pelos estudantes.

A pesquisa de Boyce et al. (2010) salienta que os estilos típicos de aprendizagem dos estudantes de contabilidade não são adequados para a aquisição de competências genéricas. Segundo os autores, algumas implicações são trazidas para os educadores de contabilidade, no sentido de reforçar ainda mais seu comprometimento com a estratégia de aprendizagem adotada, por poder influenciar a postura do estudante.

Dallimore et al. (2010) argumentam que é importante estimular a participação e o conforto dos alunos para melhorar o aprendizado. Segundo os autores, quanto mais estimulada for a participação do estudante, mais ele estará à vontade para colaborar efetivamente com a aula, prepararse previamente para as discussões e, com isso, aumentar o nível de aprendizado. Para tal função, a 
pesquisa buscou mostrar a efetividade do uso das discussões em classe, principalmente utilizando grupos pequenos, a fim de desenvolver nos estudantes habilidades de participação e comunicação, além de aumentar o aprendizado.

\subsubsection{Taxonomia de Bloom}

A Taxonomia de Bloom, para Santana et al. (2008), é um instrumento de classificação de objetivos de aprendizagem de forma hierárquica (do mais simples para o mais complexo). Pode ser utilizada para estruturar, organizar e planejar disciplinas, cursos ou módulos instrucionais, tornando-se um instrumento adequado a ser utilizado no ensino superior. Nos últimos anos, foi avaliada e atualizada, considerando avanços estratégicos e tecnológicos incorporados ao meio educacional, desenvolvendo outros domínios além do cognitivo (afetivo e psicomotor), por vezes negligenciados quando estabelecidos os objetivos de aprendizagem.

Santana et al. (2008) discorrem que a Taxonomia forneceu uma base sólida para os currículos, tratando sobre o que ensinar e, no processo da avaliação, sobre o que avaliar. A taxonomia trouxe a possibilidade de padronização da linguagem para o meio acadêmico, o que gerou novas discussões ao redor de assuntos como os relacionados à definição de objetivos instrucionais.

A Taxonomia têm basicamente três domínios básicos: cognitivo, afetivo e psicomotor (BLOOM, 1973), que resumidamente são assim caracterizados: Cognitivo - aquisição de um novo conhecimento, relacionado a aprender, ao reconhecimento de fatos, tendo alguns procedimentospadrões e subdividido em seis subcategorias em hierarquia (conhecimento, compreensão, aplicação, análise, síntese e avaliação); Afetivo - relacionado a sentimentos e posturas, na área emocional, incluindo relacionamentos, atitudes e responsabilidades; Psicomotor - relacionado a habilidades manuais ou físicas.

Segundo Ferraz e Belhot (2010), embora todos os três domínios (cognitivo, afetivo e psicomotor) tenham sido amplamente discutidos e divulgados em momentos e por pesquisadores diferentes, o domínio cognitivo é o mais conhecido e utilizado. Essa diferença em relação à popularidade o domínio cognitivo poderia ser caracterizada pelas estratégias de ensino utilizadas, que levariam ao estudo de estilos de ensino e aprendizagem, e à organização dos processos de aprendizagem para estimular o desenvolvimento cognitivo.

Bloom, Krathwohl e Masia (1974) classificaram o domínio cognitivo em seis categorias hierárquicas, onde se supõe que o indivíduo domine a anterior antes de atingir a próxima. A seguir, são descritos cada um dos domínios cognitivos, conforme colocado por Bloom, Krathwohl e Masia (1974):

- Conhecimento: processo no qual o indivíduo deve reproduzir com exatidão as informações como uma data, relato, procedimento, fórmula, entre outros, sendo que essa habilidade pode envolver lembrar uma significativa quantidade de informações. Verbos que representam essa categoria: enumerar, definir, descrever, identificar, denominar, listar, nomear etc.;

- Compreensão: é a primeira categoria que requer elaboração ou modificação de uma informação, ainda sem complexidade, compreendendo e dando significado ao conteúdo. Verbos que representam essa categoria: alterar, construir, converter, decodificar, definir, descrever etc.;

- Aplicação: reúne os processos de uma situação genérica para uma específica, habilidade de utilizar as informações em situações concretas. Verbos que representam essa categoria: aplicar, alterar, programar, demonstrar, desenvolver, descobrir, dramatizar, empregar, ilustrar, interpretar, manipular, modificar etc.;

- Análise: separa informações de elementos compostos, identificando aspectos centrais, constata sua lógica e possíveis diferenças, subdividindo um conteúdo em partes meno- 
res para entender o todo. Verbos que representam essa categoria: analisar, reduzir, classificar, comparar, contrastar, determinar, deduzir, diagramar, distinguir, diferenciar etc.;

- Síntese: o indivíduo reúne as informações para criar algo novo, envolvendo a produção de uma comunicação única. Verbos que representam essa categoria: categorizar, combinar, compilar, compor, conceber, criar, desenhar etc.;

- Avaliação: processo cognitivo mais complexo, que envolve a confrontação de uma informação com um critério, fazendo um julgamento de valor. Verbos que representam essa categoria: avaliar, averiguar, escolher, comparar, concluir, contrastar, criticar, decidir, defender, discriminar, explicar e interpretar.

A taxonomia padronizou a linguagem no meio acadêmico, o que gerou o início de novas discussões ao redor dos assuntos relacionados à definição de objetivos instrucionais. Por isso, instrumentos de aprendizagem puderam ser trabalhados de forma mais integrada e estruturada, considerando os avanços tecnológicos que podiam prover novas e diferentes ferramentas para facilitar o processo de ensino e aprendizagem.

Dessa forma, tendo em vista os objetivos de aprendizagem planejados, o docente pode escolher a modalidade didática mais adequada para incentivar a adoção de uma abordagem de estudo profunda pelo aluno, tornando-o ativo na construção do próprio conhecimento.

Considerando-se as mudanças recentes na contabilidade no Brasil, com a convergência às IFRS e a ênfase decorrente na capacidade de análise crítica, julgamento e decisão, cada vez mais é buscada a autonomia do aluno no processo de aprendizagem. Isso é desejável no ensino superior e, muito mais, como no contexto dessa pesquisa, no ensino de pós-graduação.

\section{3}

\section{METODOLOGIA}

Nesta pesquisa, a abordagem utilizada é predominantemente qualitativa. A pesquisa qualitativa busca compreender, descrever e interpretar os fatos e fenômenos, e é um tipo de pesquisa destinada geralmente a situações complexas e particulares (MARTINS; THEÓPHILO, 2009). A pesquisa também pode ser considerada exploratório-descritiva, por procurar conhecer um campo de estudo ainda pouco estudado e descrever a situação dentro do ambiente de aprendizagem de um programa de pós-graduação (GIL, 2002).

Foi realizada uma pesquisa qualitativa e quase-experimental ex post facto, pois permite analisar relações estabelecidas no fenômeno investigado, além de lidar com variáveis não manipuláveis, comuns às ciências sociais aplicadas (MARTINS; THEÓPHILO, 2009). Isso ocorre porque o objeto de estudo são indivíduos, o que dificulta o controle absoluto sobre todas as variáveis em análise, o que leva a tal classificação de pesquisa. Também há alinhamento da presente pesquisa à proposta da pesquisa-ação. Segundo Gil (2002), nesse tipo de pesquisa há um envolvimento ativo do pesquisador, bem como se observa a ação de diferentes pessoas ou grupos.

A aplicação da pesquisa ocorreu em uma turma de um programa de pós-graduação em Ciências Contábeis, na disciplina Controladoria, durante os meses de outubro e novembro de 2012, em uma instituição de ensino privada, cujo nome não é aqui mencionado devido ao que foi acordado com a instituição para viabilizar e permitir a realização da pesquisa.

O curso como um todo abrange temas de contabilidade gerencial e financeira, dando maior ênfase às disciplinas de Contabilidade Gerencial. A disciplina tem carga horária de 32 horas/aula, sendo utilizadas ao longo das aulas as modalidades didáticas: aula expositiva, aplicação de exercício, aplicação de casos para ensino e discussões em pequenos grupos.

O curso foi ministrado no período noturno, tendo alunos que, na totalidade, trabalhavam durante o dia e frequentavam as aulas após o período de trabalho. Os alunos estavam no primeiro semestre, sendo a disciplina introduzida no segundo bimestre em um módulo de disciplinas bási- 
cas. Eles eram graduados em áreas diversas como Economia, Administração, Ciências Contábeis e Engenharia. O docente e o conteúdo abrangido foram os mesmos nas duas aulas.

Este estudo foi conduzido em dois momentos. O primeiro foi composto por uma aula expositiva e aplicação de um exercício, modalidades didáticas comuns ao ensino superior (LOO, 2002; MAZZIONI, 2009). Em um segundo momento, na aula seguinte, abordou-se o mesmo conteúdo com outra modalidade didática, proposta para este estudo. Esta etapa visava a sugestão de uma nova abordagem a ser utilizada em sala de aula, construída conforme indicações baseadas no referencial teórico.

Nesse contexto, foi desenvolvida uma aula prática, onde as atividades, discussões e questionamentos ficaram a cargo dos alunos. Ao docente coube dar o direcionamento inicial, trazer material de apoio sobre o conteúdo (Figura 2), composto por quebra-cabeça envolvendo parte do material (Figura 3) e algumas questões de estímulo à discussão (Quadro 1).
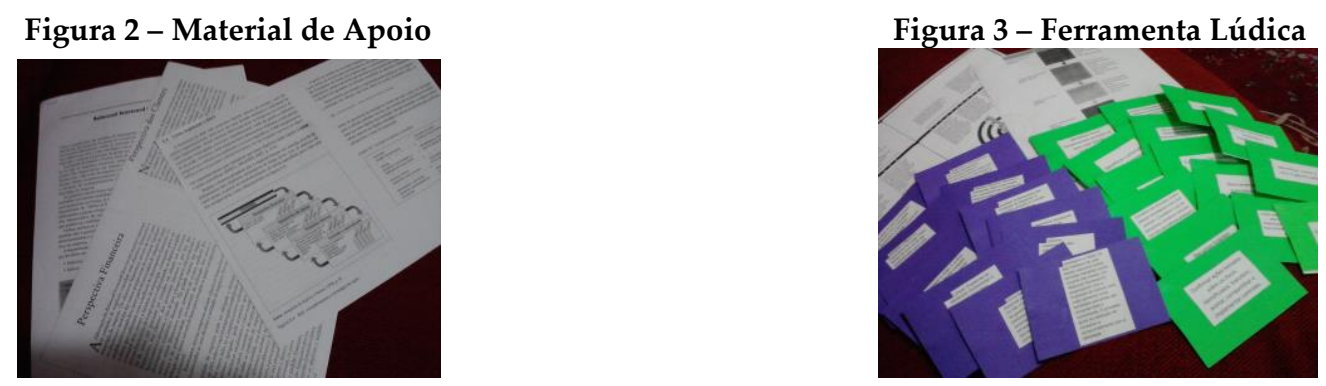

Quadro 1 - Questões orientadoras.

\begin{tabular}{|c|c|}
\hline Tema 1 - Balanced Scorecard & Tema 2 - Gerenciamento de Riscos \\
\hline $\begin{array}{l}\text { a) Identifique e explique as quatro perspectivas do Balanced } \\
\text { Scorecard. } \\
\text { b) Observe as principais críticas relacionadas ao BSC. Você } \\
\text { concorda? Dê a sua opinião e justifique sua resposta para cada } \\
\text { uma delas. } \\
\text { c) Comente sobre as principais formas para implantar cada uma } \\
\text { das perspectivas do BSC em uma empresa. } \\
\text { d) Organize as etapas para implantação do BSC em uma } \\
\text { empresa utilizando o Processo de Gestão. }\end{array}$ & $\begin{array}{l}\text { a) Sobre o Gerenciamento de Risco, aponte os } \\
\text { principais aspectos relacionados à evolução } \\
\text { histórica do tema. } \\
\text { b) Comente as principais alternativas relacionadas à } \\
\text { avaliação de riscos. } \\
\text { c) Organize as principais necessidades dos usuários } \\
\text { em relação aos relatórios internos de risco e as } \\
\text { respostas sugeridas. }\end{array}$ \\
\hline
\end{tabular}

A ideia era que os alunos organizassem as informações, discutissem o conteúdo e, ao final, propusessem uma resposta às questões orientadoras, bem como uma solução para a atividade lúdica proposta. Para cada tema havia uma proposta distinta em relação ao quebra-cabeça: um fluxograma e uma tabela (Figura 3).

A turma foi dividida em pequenos grupos. Na primeira hora e meia, trabalharam um tema e, na hora e meia seguinte, outro, tendo a aula duração total de três horas. Nas duas partes da aula os objetivos a serem alcançados foram os mesmos. Os assuntos eram independentes e, por isso, a sequência do material não fez diferença para o acompanhamento. Os temas ministrados envolveram conceitos relacionados ao Balanced Scorecard e ao Gerenciamento de Riscos.

A construção desta proposta tomou como base:

- O Ciclo de Kolb, que estimula a experiência em detrimento à passividade, apresentado na seção 2.1;

- O objetivo do docente para disciplina, de estimular a participação do aluno e sua constante relação entre a teoria estudada e a prática, como sugere a abordagem de aprendizagem profunda, descrita na seção 2.2.1; 
- O desenvolvimento do domínio cognitivo em todos os seus níveis, considerando a Taxonomia de Bloom, discutida na seção 2.2.2.

A aprendizagem vivencial, ilustrada pelo Ciclo de Kolb, tira o foco do professor e centra o aprendizado no aluno, dando a ele a capacidade de selecionar a informação mais relevante sob o seu ponto de vista, além de aprender fazendo, ou seja, por meio de sua própria experiência com a atividade. $\mathrm{O}$ professor atua como facilitador do processo de ensino.

Ao término da aula, esperava-se que o aluno tivesse adquirido senso crítico e pró-atividade na busca de solução de problemas, características típicas do que Spencer (2003) defende como sendo as de um aluno profundo. A avaliação dessas características se deu por meio de análise de conteúdo de questões abertas sobre os conceitos principais da aula, analisando a assertividade e o uso dos diferentes verbos sugeridos em cada uma das seis categorias do domínio cognitivo propostas por Bloom, Krathwohl e Masia (1974). As questões sobre o conteúdo foram aplicadas nas duas aulas, conforme mostra o Quadro 2.

Quadro 2 - Questões sobre o conteúdo discutido nas aulas.

\begin{tabular}{|c|c|}
\hline Tema 1 - Balanced Scorecard & Tema 2 - Gerenciamento de Riscos \\
\hline \multicolumn{2}{|c|}{ Aula 1} \\
\hline $\begin{array}{l}\text { Em sua opinião, como a ferramenta BSC se relaciona ao } \\
\text { processo de gestão? } \\
\text { Quais as vantagens em utilizar o BSC no dia-a-dia } \\
\text { empresarial? }\end{array}$ & $\begin{array}{l}\text { Em sua opinião, como a ferramenta de Gerenciamento de } \\
\text { Riscos se relaciona ao processo de gestão? } \\
\text { Quais as vantagens em utilizar o Gerenciamento de Riscos } \\
\text { no dia-a-dia empresarial? }\end{array}$ \\
\hline \multicolumn{2}{|c|}{ Aula 2} \\
\hline $\begin{array}{l}\text { Cite pontos novos que você discutiu sobre o BSC na aula } \\
\text { de hoje. } \\
\text { Quais as vantagens em utilizar o BSC no dia-a-dia } \\
\text { empresarial? }\end{array}$ & $\begin{array}{l}\text { Cite pontos novos que você discutiu sobre Gerenciamento } \\
\text { de Riscos na aula de hoje. } \\
\text { Quais as vantagens em utilizar o Gerenciamento de Riscos } \\
\text { no dia-a-dia empresarial? }\end{array}$ \\
\hline
\end{tabular}

A modalidade didática adotada na Aula 2 pretendeu auxiliar no estímulo ao desenvolvimento cognitivo proposto pela Taxonomia de Bloom, desenvolvendo os níveis cognitivos. A sugestão aqui proposta mescla leitura, discussão em grupo e resolução de problemas, além de estimular a participação do estudante, fato que sabidamente contribui para o seu aprendizado (DALLIMORE et al., 2010; OPDECAM; EVERAERT, 2012). Os grupos formados variaram entre quatro e cinco estudantes. Durante todo o tempo o docente acompanhou os alunos visando esclarecer dúvidas, propor novas questões de estímulo e direcionar o objetivo do trabalho.

Adicionalmente ao professor, um observador acompanhou as duas aulas e aplicou um teste ao final de cada aula aos alunos, visando comparar a aprendizagem e as percepções às diferentes modalidades de ensino adotadas. Sintetizando, os dados coletados junto aos estudantes foram: resposta às questões de estímulo (Quadro 1) e à atividade lúdica proposta (Figura 3), resposta a um questionário aberto com perguntas adicionais sobre os conhecimentos adquiridos em cada aula (Quadro 2) e resposta a um questionário fechado da percepção dos alunos sobre a aula, ressaltando as seis diferentes dimensões do domínio cognitivo da Taxonomia de Bloom (Quadro 3).

O questionário (Quadro 3) foi aplicado utilizando a Escala Likert, adaptando o modelo de Benjamim Junior (2011), tendo como opções de resposta: Concordo; Concordo parcialmente; Não concordo nem discordo; Discordo parcialmente e Discordo. O seu objetivo foi refletir a percepção dos alunos em relação a sua percepção de aprendizado sobre cada um dos domínios. Assim, cada questão elaborada tinha correspondência direta a uma das categorias analisadas. 
Quadro 3 - Questões de avaliação sobre as categorias do domínio cognitivo.

\begin{tabular}{|c|c|}
\hline Questão de avaliação & Categoria Cognitiva \\
\hline 1. A aula me proporcionou reconhecer conteúdos estudados anteriormente. & Conhecimento \\
\hline $\begin{array}{l}\text { 2. Ao participar da aula tive a oportunidade de relacionar os conhecimentos adquiridos com } \\
\text { conhecimentos que já possuía. }\end{array}$ & Compreensão \\
\hline 3. Durante minha participação tive a oportunidade de aplicar conhecimentos que já possuía. & Aplicação \\
\hline 4. A aula me proporcionou a possibilidade de praticar a análise dos problemas. & Análise \\
\hline $\begin{array}{l}\text { 5. Ao participar da aula exercitei minha capacidade de fazer julgamentos baseados em critérios } \\
\text { ou normas. }\end{array}$ & Síntese \\
\hline $\begin{array}{l}\text { 6. A aula me proporcionou a oportunidade de reorganizar, de forma criativa, conhecimentos } \\
\text { que já possuía, por meio da experiência vivencial dos problemas ao âmbito empresarial }\end{array}$ & Avaliação \\
\hline
\end{tabular}

Fonte: Adaptado de Benjamim Junior (2011).

Os questionários foram desenvolvidos pelos autores, com base na revisão de literatura, nos objetivos de aprendizagem em cada tema e no material didático desenvolvido. Ainda, foi realizada uma análise por meio da observação participante tanto do professor como do observador, que foi somada à análise de conteúdo das respostas dos questionários dos alunos (Quadro 3).

No que tange às aulas, a primeira teve como modalidade didática a aula expositiva, seguida pela aplicação de um exercício. Ao todo, a turma era formada por 26 alunos, dos quais 21 assistiram a essa aula, sendo que os demais faltaram à aula e por isso não participaram.

A segunda aula utilizou a modalidade didática proposta no item 3, que entrelaça conceitos relacionados a aulas práticas, aprendizagem facilitada e cooperativa, com o desenvolvimento de todos os níveis do domínio cognitivo da Taxonomia de Bloom. Do total de alunos, 19 assistiram à segunda aula. Ao todo, 16 alunos participaram das duas aulas, que foram os considerados para as análises descritas na próxima seção. No item seguinte, os resultados são apresentados, analisados e comentados conforme os objetivos estabelecidos para a pesquisa.

\section{APRESENTAÇÃO E ANÁLISE DE RESULTADOS}

As seções seguintes descrevem a aplicação do procedimento e os resultados alcançados, abrindo uma discussão sobre a aplicabilidade do método e suas limitações.

\subsection{Aplicação}

Explorando os dados coletados, notou-se pela observação participante do professor e do observador que, mesmo na aula expositiva, com a provocação do professor, os alunos foram instados a participar e cooperar com o conteúdo e construção da aula. Nessa modalidade, porém, percebeu-se uma incidência maior de demonstrações de cansaço, como bocejos, recostar-se na parede etc. Além disso, mesmo o docente conseguindo uma boa participação dos alunos (13 dos 21 presentes contribuíram em algum momento da aula), alguns discentes apresentaram uma postura de passividade, esperando pela explanação do conteúdo por parte do professor e resolução das atividades propostas sem inciativa de tentar resolvê-las de forma prévia.

A aplicação do exercício foi o momento mais delicado da aula, pois os alunos têm entendimentos diferentes sobre o que se espera como resposta e, mesmo sendo uma resolução de exercício em grupo, esperaram pela resposta correta e única por parte do professor. No geral, eles chegaram ao que se esperava para a atividade, porém tiveram uma alta dependência das instruções do docente sobre um caminho para resolver o problema proposto.

$\mathrm{Na}$ aula prática os alunos foram chamados a participar desde o primeiro minuto, uma vez que a construção da resposta e, por consequência, da aula, ficou a cargo deles. O caráter lúdico da tarefa remeteu alguns alunos às atividades que eles desenvolviam na infância, em experiências escolares anteriores. Outros alunos ficaram assustados com a quantidade de material disponibili- 
zado para consulta e manipulação, gerando murmúrios e reclamações sobre um suposto excesso de atividades. Foi interessante notar como cada indivíduo lida de forma diferente com a atividade que está sendo proposta. Alguns alunos dividiram o material (Figuras 2 e 3), tirando os grampos, para que todos pudessem fazer a leitura.

Outros preferiram discutir previamente a forma de trabalho que o grupo iria desenvolver. No decorrer da atividade, foram surgindo dúvidas sobre os assuntos nos grupos, as quais o docente fez explicações pontuais dentro de cada grupo, existindo também um auxílio mútuo entre os próprios alunos para sanar as dúvidas. Assim, além dos objetivos de aprendizagem relacionados ao domínio cognitivo da Taxonomia de Bloom, os estudantes puderam desenvolver objetivos também do domínio afetivo, trabalhando em grupo, tendo que apresentar e defender seu ponto de vista, ouvindo e reagindo a opiniões diferentes da sua, mas buscando chegar a um consenso.

Outra percepção que se teve foi a de que eles preferiram resolver, quase na totalidade dos casos, as questões relacionadas aos textos deixando o quebra-cabeça para o final. Também se notou que o maior grau de envolvimento e familiaridade com o assunto e com a nova tarefa proposta se deu apenas uma hora depois de iniciada a atividade. Neste ponto, surgiram manifestações interessantes dos alunos, como um grupo que se propôs a escrever seu próprio texto sobre o assunto. No geral, notou-se que todos os alunos se envolveram ativamente com a atividade proposta.

A segunda parte da aula, quando a mesma atividade foi proposta a cada um dos grupos, mas agora envolvendo um novo assunto, houve o benefício da curva de aprendizagem, uma vez que os discentes já estavam inteirados com a forma de trabalho. O que se percebeu foi que ocorreu uma maior interação dos alunos com o conteúdo e com o conhecimento, pois eles se manifestavam mais sobre impressões e participavam ativamente. Alguns explicavam aos demais o que entenderam, ou trocavam informações com os colegas, dando exemplos do que acontece em suas experiências pessoais no trabalho.

Duas horas depois de iniciada a aula, também se notou que, mesmo nessa atividade onde o aluno é incentivado a participar mais ativamente, alguns manifestaram cansaço, bocejando, apoiando o rosto nas mãos e na mesa, passando a mão pelo rosto e escorregando pelas cadeiras. No entanto, deve-se considerar que são alunos-trabalhadores, atendendo a um curso de pósgraduação no horário noturno. Ao final, todos conseguiram responder às questões orientadoras. Alguns manifestaram, em comentários informais, predileção pela aula dessa forma, outros disseram preferir assistir a uma aula tradicional.

\subsection{Resultados}

Optou-se por analisar apenas as respostas oriundas dos alunos que participaram das duas aulas (16 ao todo), por permitirem comparar a efetividade de uma ou outra modalidade. Um dos questionários disponibilizados aos alunos visava identificar a percepção deles sobre a contribuição da aula para o desenvolvimento das dimensões do domínio cognitivo da Taxonomia de Bloom (Quadro 3). Nesse caso, os estudantes foram questionados sobre a contribuição da aula para cada uma dos níveis. A tabela seguinte apresenta a resposta sobre a percepção dos alunos para a aula 1.

Tabela 1 - Percepção dos alunos sobre as categorias do domínio cognitivo de Bloom (Aula 1 - Expositiva).

\begin{tabular}{lcccccc}
\hline \multicolumn{1}{c}{ Opções } & Conhecimento & Compreensão & Aplicação & Análise & Síntese & Avaliação \\
\hline Concordo & 7 & 10 & 11 & 12 & 9 & 7 \\
Concordo parcialmente & 8 & 5 & 4 & 4 & 5 & 7 \\
Não concordo nem discordo & 1 & 1 & - & - & 1 & 1 \\
Discordo parcialmente & - & - & - & - & 1 & - \\
Discordo & - & - & 1 & - & - & 1 \\
\hline
\end{tabular}


Nota-se que, em todas as categorias, as opções "concordo" e "concordo parcialmente" prevalecem, sendo superior a $80 \%$ dos casos. A maior parte dos alunos convergiu para a percepção de que os objetivos de aprendizagem da aula eram focados em compreensão, aplicação e análise, com maior ênfase nesses dois últimos.

Tabela 2 - Percepção dos alunos sobre as categorias do domínio cognitivo de Bloom (Aula 2 - Prática).

\begin{tabular}{lcccccc}
\hline \multicolumn{1}{c}{ Opções } & Conhecimento & Compreensão & Aplicação & Análise & Síntese & Avaliação \\
\hline Concordo & 9 & 7 & 9 & 9 & 7 & 7 \\
Concordo parcialmente & 6 & 8 & 5 & 7 & 8 & 9 \\
Não concordo nem discordo & 1 & 1 & 2 & - & 1 & - \\
Discordo parcialmente & - & - & - & - & - & - \\
Discordo & - & - & - & - & - & - \\
\hline
\end{tabular}

A mesma percepção tida na Aula 1 (Tabela 1) repetiu-se na aula 2 (Tabela 2), ou seja, as opções "concordo" e "concordo parcialmente" prevalecem, sendo superiores a $80 \%$ dos casos. Nota-se que na Aula 2, nenhum aluno optou pelas alternativas "discordo" e "discordo parcialmente". Nessa aula, os alunos parecem convergir para a percepção de uma abrangência maior dos níveis relacionados aos objetivos de aprendizagem, indo desde o conhecimento até a avaliação.

De alguma maneira eles parecem perceber essa aula como mais "completa" em termos dos objetivos, atingindo todos os níveis da hierarquia do domínio cognitivo da Taxonomia de Bloom. Mas, ao mesmo tempo, as respostas estão mais distribuídas entre a concordância total e parcial. No mais, as diferenças foram pequenas, de forma a não ser possível concluir se houve predileção por uma ou outra forma de modalidade didática da parte dos alunos por este instrumento.

O exercício de análise de conteúdo realizado também revelou que ambas as aulas contribuíram para o conhecimento do aluno sobre o conteúdo proposto. Deve-se ressaltar, no entanto, que por serem aulas seguidas, em uma mesma turma, sobre os mesmos assuntos, é comum haver uma contaminação dos resultados, pois os alunos já foram expostos aos temas.

Outro ponto a considerar são os estilos de aprendizagem dos alunos: enquanto alguns podem aprender fazendo, outros aprendem ouvindo ou lendo. Assim, mais do que buscar uma modalidade única, superior às demais, deve-se considerar o benefício de adotar mais de uma modalidade didática de forma a contemplar os diferentes estilos de aprendizagem.

\subsection{Discussão}

De forma geral, não foram percebidas diferenças significativas entre as duas modalidades de ensino utilizadas. Algumas considerações e questões podem ser levantadas sobre esse resultado. O questionários apresentado no Quadro 3 refletiu a percepção dos alunos, exclusivamente. Tal percepção tem a limitação de compreensão sobre o que cada um entende para os seis diferentes níveis do domínio cognitivo da Taxonomia de Bloom, mesmo que se tenha tentado traduzir a essa categoria a uma questão mais compreensível por eles.

$\mathrm{Na}$ avaliação do conteúdo, ambas as metodologias se mostraram eficazes no sentido de auxiliar o aluno a alcançar as diferentes etapas. Por outro lado, os resultados indicam que não necessariamente há uma hierarquização entre as categorias, como sugerido por Bloom, Krathwohl e Masia (1974); uma vez que houve manifestação de alunos que alcançaram a categoria "Avaliação", mesmo que nenhum aluno tenha mostrado indícios da etapa anterior ("síntese"). Isso pode reforçar o ponto levantado acima sobre a compreensão de cada nível.

Outra possível interferência na pesquisa é que, para que o aluno alcance as diferentes etapas sugeridas, talvez seja necessário mais tempo do que o transcorrido entre as duas aulas (uma semana). Logo, não se consegue pelos instrumentos utilizados avaliar a verdadeira extensão do 
conhecimento retido pelos alunos, pois implica em etapas como criticar e recriar, que estariam mais diretamente ligadas às abordagens de estudo superficial ou profunda.

Ainda há que se referir ao conteúdo abordado. Alguns conteúdos, por serem mais extensos e complexos, podem levar algum tempo para assimilação. Além disso, cada aluno tem uma história de vida diferenciada, o que também pode ter impactos na retenção de conhecimento e no próprio interesse e motivação do aluno pelo conteúdo, questões que não foram levadas em conta na avaliação. Esta percepção está de acordo com o que afirma McCarthy (2010), de que o nível social e o background cultural podem influenciar as preferências pelo estilo de aprendizado.

Para a segunda aula, especificamente, os alunos já tinham contado com uma exposição ao mesmo conteúdo na aula imediatamente anterior, em uma modalidade didática distinta, de forma que não é possível medir o quanto isso afetou, e se positiva ou negativamente, o desempenho e assimilação do conteúdo na segunda aula. Loo (2002) argumenta que diferentes métodos de ensino favorecem o alcance das diferentes abordagens do Ciclo de Kolb. Dessa forma, pode-se entender que talvez as abordagens tenham sido complementares no que diz respeito a desenvolverem diferentes vertentes de aprendizagem pelos alunos. Hosal-Akman e Simga-Mugan (2010) pesquisaram sobre o efeito dos métodos de ensino para o desempenho acadêmico. Ao final, da mesma forma que nesta pesquisa, não houve diferença significativa entre os métodos.

\section{CONSIDERAÇÕES FINAIS}

A pesquisa visou analisar o impacto na utilização de diferentes estratégias de ensinoaprendizagem utilizadas pelos professores considerando a forma de estudo que se pretende que os alunos adotem, nos cursos de pós-graduação em Ciências Contábeis. Para isso, uma turma de pósgraduação foi exposta a diferentes modalidades didáticas em duas aulas do seu curso.

Respondendo à questão de pesquisa, de forma geral, não foram percebidas diferenças significativas entre as duas modalidades didáticas. No que tange à abordagem superficial e profunda, a modalidade proposta para a segunda aula foi mais efetiva no sentido de garantir a participação dos alunos, bem como seu envolvimento no sentido de buscar aplicações práticas e estabelecer relações entre a teoria e a prática.

Já no que diz respeito às categorias inerentes ao domínio cognitivo da Taxonomia de Bloom, os dois métodos se mostraram eficazes no alcance das diferentes vertentes investigadas. Ressalte-se, no entanto, que a segunda modalidade, aula prática, permite desenvolver objetivos relacionados também ao domínio afetivo.

Outro ponto a ser considerado são os estilos de aprendizagem dos alunos: enquanto alguns aprendem fazendo, outros aprendem ouvindo ou lendo. Assim, mais do que buscar uma modalidade única, superior às demais, deve-se considerar o benefício de adotar mais de uma modalidade didática de forma a contemplar os diferentes estilos de aprendizagem.

Por meio do referencial teórico, a pesquisa mostrou a necessidade do envolvimento docente no que tange a proporcionar aos alunos novas formas de contato com os conteúdos aos quais eles são expostos todos os dias. Na observação em campo, ficou claro que tais abordagens geram maior envolvimento por parte do estudante.

Sugere-se, para estudos posteriores, a replicação desse método com um número maior de alunos, bem como o acompanhamento por um período maior de tempo e/ou utilizando outras técnicas de pesquisa que permitam ampliar o conhecimento da metodologia proposta no comportamento do discente. Também seria interessante saber se o trabalho pré-aula, por parte do docente, deve ser diferenciado no que tange a questões como: tempo empregado, preparo prévio para a aula, recursos envolvidos, entre outros. 


\section{REFERÊNCIAS}

BENJAMIM JUNIOR, V. Teoria da complexidade e contabilidade: estudo da utilização da aprendizagem baseada em problemas como abordagem complexa no ensino da contabilidade. São Paulo, 2011. Dissertação (Mestrado em Contabilidade e Controladoria) - Programa de Pós Graduação em Ciências Contábeis, Faculdade de Economia, Administração e Contabilidade da Universidade de São Paulo, 2011.

BOYCE, G.; WILLIANS, S.; KELLY, A.; YEE, H. Fostering deep and elaborative learning and generic (soft) skill development: the strategic use of case studies in accounting education. Accounting Education, v. 10, n. 1, 2001.

BLOOM, B. S. Taxionomia de objetivos educacionais. Porto Alegre: Globo, 1973.

BLOOM, B. S.; KRATHWOHL, D. S.; MASIA, B. B. Taxonomia de objetivos educacionais, domínio afetivo. Porto Alegre: Globo, 1974.

BUCKHAULTS, J.; FISHER, D. Trends in Accounting Education: Decreasing Accounting Anxiety and Promoting New Methods. Journal of Education for Business, v. 86, 2011.

DALLIMORE, E. J.; HERTENSTEIN, J. H.; PLATT, M. B. Class Participation in Accounting Courses: Factors That Affect Student Comfort and Learning. American Accounting Association, v. 25, n. 4, 2010.

DEAQUINO, C. T. E. Como aprender: andragogia e as habilidades de aprendizagem. São Paulo: Pearson Prentice Hall, 2007.

FERRAZ, A. P. C. M; BELHOT, R. V. Taxonomia de Bloom: revisão teórica e apresentação das adequações do instrumento para definição de objetivos educacionais. Gestão de Produção, v.17, n. 2, 2010.

GIL, A. C. Como elaborar projetos de pesquisa. 4. ed. São Paulo: Atlas, 2002.

GODOY, A. S. Didática para o ensino superior. São Paulo: Iglu, 1988.

HALL, M.; RAMSAY, A.; RAVEN; J. Changing the learning environment to promote deep learning approaches in first-year accounting students. Accounting Education, v. 13, n. 4, 2004.

HOSAL-AKMAN, N.; SIMGA-MUGAN, C. An assessment of the effects of teaching methods on academic performance of students in accounting courses. Innovations in Education and Teaching International, v. 47, n. 3, 2010.

KRASILCHICK, M. Reformas e realidade: o caso de ensino das ciências. São Paulo em Perspectiva, v. 14, n. 1, 2000.

LEAL, D. T. B.; CORNACHIONE JR., E. A aula expositiva no ensino da contabilidade. Revista Contabilidade Vista \& Revista, v. 17, n. 3, 2006. 
LIMA, S. J. Aprendizagem Cooperativa: um experimento no ensino da contabilidade. São Paulo, 2012. Dissertação (Mestrado em Contabilidade) - Programa de Pós Graduação em Ciências Contábeis, Faculdade de Economia, Administração e Contabilidade da Universidade de São Paulo, 2012.

LOO, R. A meta-analitic examination of Kolb's learning style preferences among business majors. Journal of Education for Business, v. 77, n. 5, 2002.

LUCKESI, C. C. Filosofia da educação. São Paulo: Cortez, 1994.

MACHADO, N. J. A Universidade e a organização do conhecimento: a rede, o tácito, a dádiva. Estudos Avançados, v. 15, n. 42, 2001.

MARTINS, G. A.; THEÓPHILO, C. R. Metodologia de investigação científica para ciências sociais aplicadas. São Paulo: Atlas, 2009.

MAZZIONI, S. As estratégias utilizadas no processo de ensino-aprendizagem: concepções de alunos e professores de ciências contábeis. In: CONGRESSO BRASILEIRO DE CONTROLADORIA E CONTABILIDADE, 9., São Paulo. Anais... São Paulo: USP, 2009.

MCCARTHY, M. Experiential learning theory: from theory to practice. Journal of Business $\mathcal{E}$ Economics Research, v. 8, n. 5, 2010.

OPDECAM, E.; EVERAERT, P. Improving student satisfaction in a first-year undergraduate accounting course by team learning. Issues in Accounting Education, v. 27, n. 1, 2012.

PERRY, R. P.; SMART, J. C. Effective teaching in higher education: research and practice. New York: Agathon Press, 1997.

PETRUCCI, V. B. C.; BATISTON, R. R. Estratégias de ensino e avaliação de aprendizagem em contabilidade. In: PELEIAS, I. R. (Org.) Didática do ensino da contabilidade. São Paulo: Saraiva, 2006.

RAMSDEN, P. Learning to teach in Higher Education. New York: Palmer, 2000.

SANTANA, J. J. B. J.; PEREIRA, D. M. V. G.; LOPES, J. E. G. Análise das habilidades cognitivas requeridas dos candidatos ao cargo de contador na administração pública federal, utilizando-se indicadores fundamentados na visão da Taxonomia de Bloom. Revista de Contabilidade e Finanças, v. 9, n. 46, 2008.

SANTOS, S. M. Didática. In: SILVA, S. P. (Org.). Teoria e Prática na Educação. Catalão: Ed. UFG, 2008.

SOUZA, L. N. Role-play aplicado ao ensino da contabilidade: um estudo à luz dos estilos de aprendizagens e percepções discentes. São Paulo, 2006. Dissertação (Mestrado em Contabilidade e Controladoria) Programa de Pós Graduação em Ciências Contábeis, Faculdade de Economia, Administração e Contabilidade da Universidade de São Paulo, 2006.

SPENCER, K. Approaches to Learning and Contemporary Accounting Education. Education in a Changing Environment. Conference Proceedings, 2003. 